\title{
RECOMENDAÇÕES DE ENERGIA PARA PACIENTES ONCOLÓGICOS PEDIÁTRICOS: QUAL A META ADEQUADA?
}

Vanessa Oliveiraa, Patricia Zamberlan ${ }^{b}$

a Nutricionista Supervisora / Instituto de Tratamento do Cancer Infantil (ITACI), Serviço de Onco Hematologia do Instituto da Criança do Hospital das Clínicas da FMUSP, Brasil.

b Nutricionista da EMTN / Instituto da Criança do Hospital das Clínicas da FMUSP, Brasil.

\section{INTRODUÇÃO}

A terapia nutricional (TN) é fundamental no sucesso da evolução clínica da criança ou adolescente com câncer, e tem como objetivo auxiliar na manutenção e/ou recuperação do seu estado nutricional. A implantação de protocolos de TN agiliza a introdução da terapêutica, minimiza efeitos adversos e otimiza todo o processo, desde a indicação até a monitorização e alta do paciente. Indicadores de qualidade são utilizados para monitoramento dos protocolos, e permitem analisar quais aspectos devem ser melhorados e/ou modificados.

\section{OBJETIVO}

O objetivo do estudo foi analisar um indicador de TN no decorrer do tempo a partir de sua implantação em um serviço de onco-hematologia pediátrico.

\section{METODOLOGIA}

Os dados foram coletados de prontuários (janeiro de 2016 a agosto de 2018) e incluíram volume de dieta prescrito e infundido, tipo de TN e causas da interrupção, bem como recomendações de calorias. A adequação entre o volume prescrito e o infundido foi correlacionada às recomendações calóricas, para verificar se a meta estabelecida fora atingida, conforme sistematizado pela instituição: "80\% das calorias recomendadas deveriam ser alcançadas em cinco dias em $100 \%$ dos pacientes". Os dados foram armazenados em planilha Excel ${ }^{\circledR}$ e os resultados anuais do indicador analisados no Software ®Stata 15. Para o teste de normalidade utilizou-se o teste Shapiro-Wilk e para a comparação das médias foi executado o Teste t.

\section{RESULTADOS}

Na análise de 2016 e 2017, o indicador se mostrou aquém da meta estabelecida, em virtude da condição clínica grave dos pacientes. Após busca na literatura de meta calórica mais adequada, foi proposto em 2018 considerar uma estimativa menor de alcance das necessidades calóricas para as crianças oncológicas, devido às intercorrências inerentes ao tratamento, tais como: dificuldade de se alimentar, internações prolongadas, efeitos colaterais dos medicamentos utilizados, necessidade de procedimentos invasivos e transplante de medula óssea, e assim passaram então a ter que atingir $67 \%$ de suas necessidades calóricas em até sete dias. ${ }^{1}$ Após a mudança houve melhora significativa em relação a 2017, com uma média anual de $80 \%(60 \%-2017$ vs $80 \%-2018 ; \mathrm{p}=$ 0,0105).
Figura 1: Média mensal do indicador de meta calórica do ITACI no ano de 2017

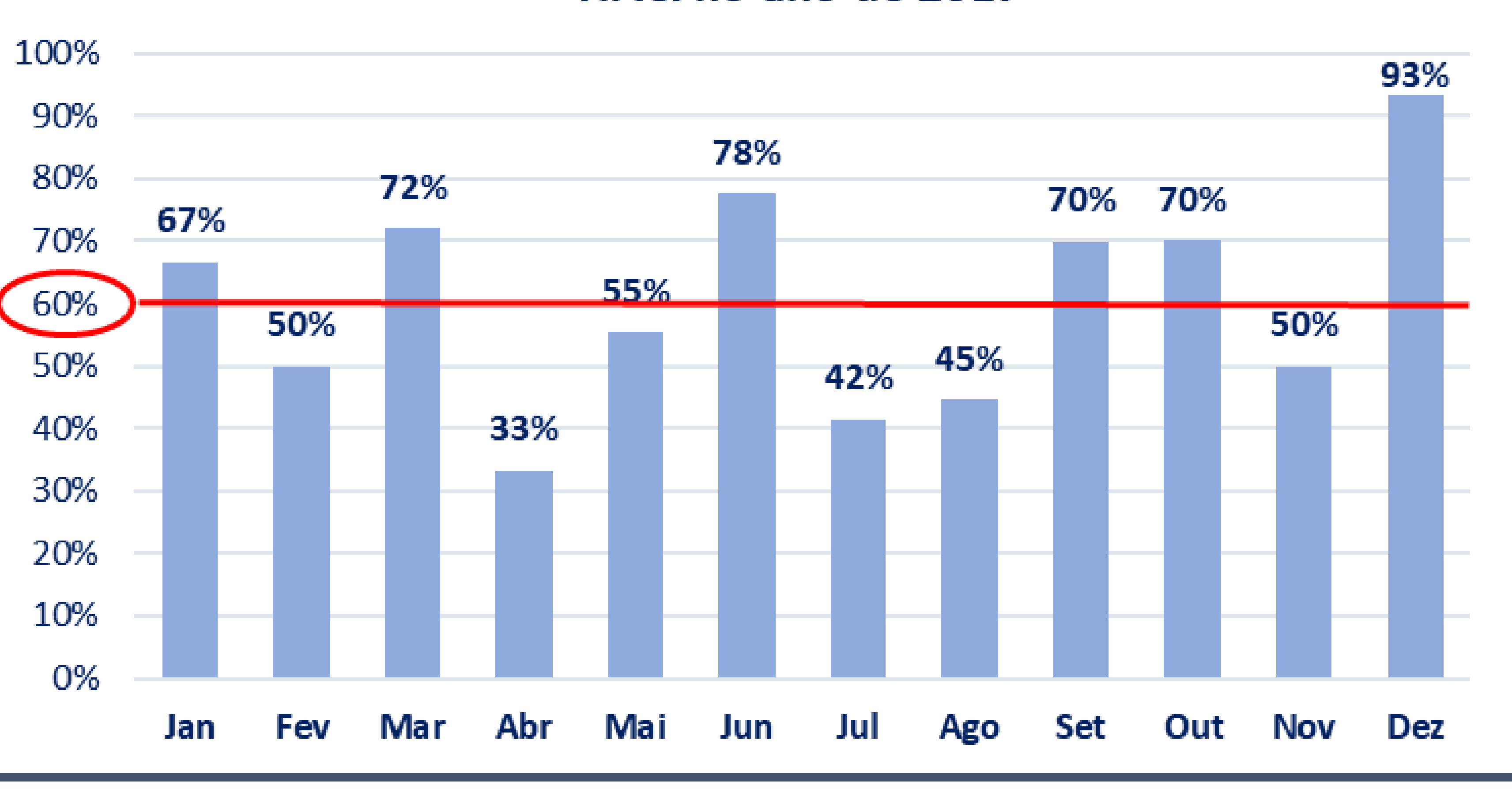

Figura 2: Média mensal do indicador de meta calórica do ITACI no ano de 2018

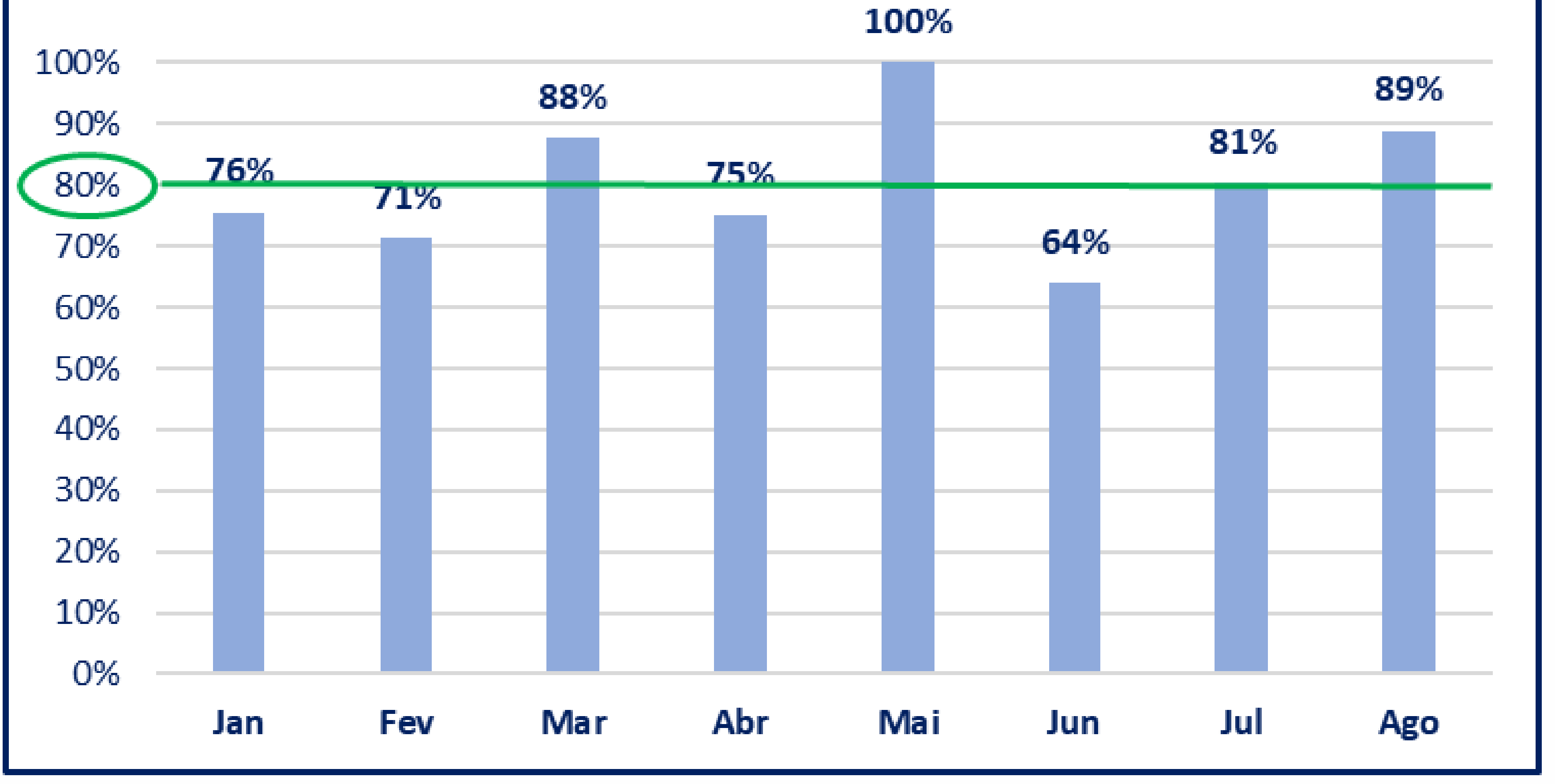

\section{CONCLUSÃO}

Protocolos institucionais devem ser periodicamente avaliados por intermédio dos indicadores de qualidade, para identificar a necessidade de reavaliação da metodologia aplicada e das metas estabelecidas. A mudança proposta estabelecida surtiu efeito, uma vez que houve melhora da meta alcançada no ano subsequente, mais condizente com a condição clínica dos pacientes atendidos. ${ }^{2}$

\section{REFERÊNCIAS}

1. Mehta NM, Skillman HE, Irving SY, Coss-Bu JA, Vermilyea $S$, Farrington EA, et al. Guidelines for the Provision and Assessment of Nutrition Support Therapy in the Pediatric Critically Ill Patient: Society of Critical Care Medicine and American Society for Parenteral and Enteral Nutrition. Vol. 41, Journal of Parenteral and Enteral Nutrition. 2017. 706-742 p. 2. Viani K, Oliveira V, Nabarrete J, Silva APA da, Feferbaum R. Nutrição e câncer infantojuvenil. 10 edição. Barueri: Manole; 2017. 316 p.

vanessa.oliveira@hc.fm.usp.br 